\title{
EL TRIBUNAL DE JUSTICIA DE LA UNIÓN EUROPEA Y EL IMPACTO DE SU RECIENTE JURISPRUDENCIA EN LA REGULACIÓN DE LA CONTRATACIÓN TEMPORAL EN ESPAÑA Y EL DERECHO A INDEMNIZACIÓN POR EXTINCIÓN DEL CONTRATO (NOTAS A TRES SENTENCIAS Y TRES AUTOS)
}

The Court of Justice of the European Union and the Impact of its Recent Jurisprudence in the Regulation of the Temporary Recruitment in Spain and the Right to Compensation for Termination of the Contract (Study of Three Judgments and Three Judicial Decrees)

\section{Eduardo Rojo Torrecilla}

Catedrático de Derecho del Trabajo y de la Seguridad Social de la Universidad Autónoma de Barcelona

\section{ABSTRACT}

El artículo estudia la jurisprudencia del Tribunal de Justicia de la Unión Europea sobre contratación laboral temporal y nombramientos temporales de personal en el sector público. Son objeto de atención tres sentencias dictadas el 14 de septiembre de 2016, y tres autos que tratan la misma temática. El TJUE ha puesto de manifiesto el incumplimiento de la normativa europea por parte de la normativa española, y abre camino a los tribunales españoles para su correcta aplicación. También 
pone de relieve que es necesaria una modificación legislativa, tanto en el ámbito laboral como en el funcionarial.

Palabras clave: TJUE, contrato, indemnización, funcionario.

The article studies the jurisprudence of the Court of Justice of the European Union on temporary employment contracts and temporary appointments of personnel in the public sector. Three judgments handed down on September 14, 2016, and three cases dealing with the same subject matter are under consideration. The CJEU has revealed the non-compliance of European legislation by Spanish law, and opens the way to the Spanish courts for its correct application. It also highlights the need for legislative changes, both in the workplace and in the civil service.

Keywords: CJEU, contract, compensation, worker, civil servant. 
El Tribunal de Justicia de la Unión Europea y el impacto de Su reciente jurisprudencia en la Regulación DE LA CONTRATACIÓN TEMPORAL EN ESPAÑA Y EL DERECHO A INDEMNIZACIÓN POR EXTINCIÓN DEL CONTRATO

\section{SUMARIO}

Sumario: 1. Introducción. 2. Estudio de la jurisprudencia del TJUE. Sentencias dictadas el 14 de septiembre de 2016. 2.1. Nombramiento de personal estatutario temporal eventual en el ámbito sanitario público. Sentencia del TJUE de 14 de septiembre de 2016 (asunto C-16/15). 2.2. ¿Nombramientos indefinidos no fijos? Sentencia del TJUE de 14 de septiembre de 2016 (asuntos C-184/15 y C-197/15). 2.3. Sobre la protección de los trabajadores temporales en caso de extinción contractual. Sentencia del TJUE de 14 de septiembre de 2016 (asunto C-596/14). 2.3.1. El supuesto fáctico. 2.3.2. La respuesta del TJUE. Análisis crítico. 3. Estudio de tres autos dictados por el TJUE (14 y 21 de septiembre de 2016, y 9 de febrero de 2017). 3.1. Discriminación del personal docente interino por no poder participar en el plan de evaluación docente. Nota al auto del Tribunal de Justicia de la Unión Europea de 21 de septiembre de 2016 (asunto C-631/15). 3.2. Medidas que prevengan el recurso abusivo a contratos de duración determinada. Auto del TJUE de 21 de septiembre de 2016 (asunto C-614/15). 3.3. Universidades. Los recortes presupuestarios y el título de doctor no son causas objetivas para tratar de diferente condición a un profesor funcionario interino que a un profesor funcionario de carrera. Notas al auto del TJUE de 9 de febrero de 2017, que sigue la saga De Diego Porras. 4. Sigue la saga De Diego Porras..., aunque sea por omisión o silencio. Sentencia del TS de 28 de marzo de 2017. Indemnización de 20 días/año para personal indefinido no fijo en caso de cobertura de la plaza y subsiguiente extinción contractual.

\section{Introducción}

Bajaban tranquilas las aguas judiciales españolas respecto a los litigios derivados de la finalización de una relación laboral de duración determinada, y señaladamente la de los contratos de interinidad, hasta que llegaron las tres sentencias del TJUE de 14 de septiembre de 2016, en especial la dictada en el asunto C-596/14, ya archiconocido como Caso De Diego Porras.

En efecto, la discusión en sede judicial, en caso de producirse, versaba sobre el cumplimiento de la normativa sobre contratación temporal del art. 15 del Texto Refundido de la Ley del Estatuto de los Trabajadores (en la actualidad Real Decreto Legislativo 2/2015, de 23 de octubre; en adelante, TRLET), y del RD 2720/1998, de 20 de noviembre. Más exactamente, de si estábamos en presencia de un auténtico contrato temporal o bien de una contratación que no respetaba la normativa citada y que por haberse celebrado en fraude de ley debía 
considerarse un contrato indefinido, y derivar de tal decisión las consecuencias pertinentes en orden a declarar la improcedencia del despido y fijar la indemnización a abonar, es decir 45 o 33 días de salario por año de servicio, según que la contratación se formalizara o no antes de la reforma laboral de 2012, y con los límites marcados en el art. 56 TRLET y la disposición transitoria quinta del RDL 3/2012, de 10 de febrero (y posterior Ley 3/2012, de 6 de julio), que actualmente ha pasado a ser la disposición transitoria undécima del TRLET.

No había discusión sobre la cuantía de la indemnización (repito sobre contratación temporal, aunque sí la habría para trabajadores indefinidos no fijos a partir de 2013 en la jurisprudencia del TS y el reconocimiento de su derecho a percibir una indemnización semejante a la de los trabajadores temporales en el momento de la extinción del contrato), dado que el art. 15.6, que daba cumplimiento a la normativa comunitaria (Directiva 1999/70/CE del Consejo, de 28 de junio de 1999, relativa al Acuerdo marco de la CES, la UNICE y el CEEP sobre el trabajo de duración determinada), había fijado el principio de igualdad de derechos entre trabajadores con contratos temporales e indefinidos, si bien «sin perjuicio de las particularidades específicas de cada una de las modalidades contractuales en materia de extinción del contrato y de aquellas expresamente previstas en la ley en relación con los contratos formativos».

Pues bien, las "particularidades especificas» se concentraban en la indemnización a la finalización del contrato, reconocida a partir de 2001 a los contratos para obra o servicio y a los eventuales por necesidades de la producción (arts. 15.1.a y b del TRLET), pero no «en los casos del contrato de interinidad y de los contratos formativos». De la indemnización inicial de ocho días se ha pasado en la actualidad a los doce días por año de servicio.

Por consiguiente, parecería que respecto a los contratos de interinidad no había conflicto entre el marco normativo interno y el comunitario, o dicho más correctamente no se había planteado en sede judicial hasta que se presentó por el Tribunal Superior de Justicia de Madrid la cuestión prejudicial que daría lugar a la sentencia del caso De Diego Porras.

Pues bien, la semana del 14 al 21 de septiembre de 2016 fue muy movida, jurídicamente hablando, para la normativa española estatal y autonómica, reguladora de las relaciones de trabajo en las Administraciones Públicas. El TJUE dictó tres sentencias y dos autos en los que queda constancia (en todas las sentencias y en un auto) de la vulneración por aquellas de la Directiva 1990/70/CE, en cuyo anexo se transcribe el acuerdo marco suscrito el 18 de marzo de 1999 por las organizaciones sindical y empresarial europea (CES, UNICE y CEEP) sobre el trabajo de duración determinada. Resoluciones que deberán ineludiblemente conducir a una modificación de la normativa laboral y administrativa de aplicación, para evitar que se sigan produciendo decisiones judiciales como las dictadas, y también para evitar dejar en manos de la judicatura todos y cada uno 
de los problemas que se planteen y correr así el riesgo de interpretaciones diversas, y en más de una ocasión contradictorias, hasta llegar a la posible unificación de doctrina por parte de la Sala de lo Social del TS.

¿Qué tesis contienen con carácter general, dichas sentencias? Que la normativa española sobre extinción de los contratos o nombramientos de personal interino, no es conforme con la citada Directiva. Que no puede tratarse de diferente (= peor) condición a estos trabajadores en el momento de extinción de su contrato que a los trabajadores indefinidos con los que se puedan comparar. Que el nombramiento de interinos puede estar justificado, pero que deja de ser tal cuando se acumulan nombramientos durante varios años, y que las plazas que ocupan dichas personas deberían salir a concurso público para su adecuada provisión, y mientras tanto que no puede extinguirse la relación de forma unilateral por decisión del empleador.

¿Se refieren las sentencias del TJUE a los restantes trabajadores temporales, por ejemplo los contratados para obra o servicio, o por necesidades de la producción? Concretamente no tratan sobre su situación, porque la normativa europea no regula la posible discriminación entre trabajadores temporales según su modalidad contractual, sino sólo entre trabajadores temporales e indefinidos comparables. Pero, una vez hecha esta afirmación jurídica, no cabe duda de que sí tienen un impacto indudable sobre todas las relaciones de trabajo de duración determinada, abriendo el camino para una necesaria reforma de la normativa laboral que proteja adecuadamente a todos ellos.

Cabe preguntarse si era necesario esperar al tirón de orejas del TJUE para reconocer que la normativa española necesitaba revisión. La respuesta es claramente que no, porque ya hace más de dos años, el 26 de marzo de 2015, la Comisión Europea había enviado una "carta de emplazamiento" al gobierno espańol por infracción de la normativa comunitaria, en concreto sobre la aplicación de la cláusula 4 del acuerdo marco y la discriminación operada en la regulación de las condiciones de trabajo entre el personal fijo o indefinido comparable y «los funcionarios con contrato de duración determinada o interinos en el sector público español». Además, ¿quién puede sorprenderse del tirón de orejas cuando los casos que han llegado al TJUE en las tres sentencias se refieren a personal estatutario, funcionarios interinos, o contratados laboral por contrato de interinidad, que venían prestando sus servicios en «interinidad permanente» desde hacía bastantes años? En cualquier caso, y también es muy importante reseñarlo, no se afirma en las sentencias del TJUE que la regulación de la contratación de duración determinada en España, en concreto de las causas que la justifican, sea incorrecta jurídicamente hablando, sino que aquello que realmente lo es versa sobre su flagrante incumplimiento en numerosas ocasiones, y que las diferencias de trato entre trabajadores temporales (laborales, estatutarios e indefinidos) no pueden estar nunca justificada por la mera duración temporal de los contratos, 
sino que debe existir una causa o razón objetiva vinculada al tipo de trabajo y a las condiciones de su desempeño.

Mi artículo, de carácter general ${ }^{1}$, se centrará en el estudio de las tres sentencias dictadas el 14 de septiembre de 2016 por el TJUE, así como también en tres autos (14 y 21 de septiembre, y 9 de febrero de 2017) que abordan la misma temática, sin olvidar una referencia a la primera sentencia dictada en unificación de doctrina en que el TS (reunido en Pleno) se pronuncia, aunque sea por omisión, sobre el impacto de aquellas en su jurisprudencia ${ }^{2}$.

Dichas sentencias han generado desde el momento de su publicación un importante debate en sede doctrinal, y han tenido su aplicación en sede judicial, con diferentes criterios. Igualmente, dichas sentencias han activado el interés judicial de dichos juzgados y tribunales en la presentación de cuestiones prejudiciales. En fin, además del intenso, muy intenso debate, en la doctrina laboralista académica y en la doctrina judicial (cuando sus señorías se pronuncian sobre cuestiones jurídicas pero no actúan investidos de su potestad jurisdiccional), no cabe olvidar, ni mucho menos, el interés del gobierno en abordar la cuestión, con el nombramiento de un grupo de expertos que elevó el mes de febrero sus «Conclusiones provisionales» y que fueron remitidas por el Ministerio de Empleo y Seguridad Social a la Mesa del Diálogo Social para la Agenda Integral por la calidad en el empleo.

\footnotetext{
${ }^{1}$ Para un seguimiento exhaustivo de todas las sentencias que se han dictado en relación con la temática objeto de la presente ponencia, es obligada la remisión al blog del profesor Ignacio Bertrán de Heredia http://ignasibeltran.com/2016/12/19/guia-practica-para-el-seguimiento-de-la-evolucionjudicial-de-la-doctrina-de-diego-porras-dic16/ (documento consultado el 22 de abril).

2 Desde la publicación de las sentencias y los autos del TJUE he prestado especial atención, en artículos doctrinales, ponencias y conferencias, y en mi blog (http://www.eduardorojotorrecilla.es/) tanto a su análisis muy detallado como a su acogimiento por las sentencias de los jueces y tribunales españoles. Por todo ello, el texto que sigue a continuación es un reflejo, como no podría ser de otra forma, de ese esfuerzo investigador realizado desde hace varios meses, convenientemente revisado y actualizado.

Las muchas, ricas, extensas e intensas aportaciones de la doctrina académica y judicial han sido objeto de atención en varias entradas de mi blog por lo que me permito remitir al mismo a todas las personas interesadas en su conocimiento y consulta Cabe ahora ańadir la referencia a dos artículos doctrinales de indudable interés, publicados recientemente y que por ello no han podido ser objeto de atención anterior. Sala Franco, Tomás. «Acerca de la Directiva comunitaria 1999/70, sobre el trabajo de duración determinada y de la sentencia del Tribunal de Justicia comunitario de 14 de septiembre de 2016, sobre las indemnizaciones no previstas en la normativa nacional española relativa a los contratos de trabajo temporal de los trabajadores interinos». Derecho de las Relaciones Laborales, núm. 3, marzo 2017, págs. 217 a 225. Martínez Miranda, Macarena: «La tutela antidiscriminatoria en la doctrina del TJUE. algunos pronunciamientos recientes», ponencia presentada en las XXVIII jornadas catalanas de Derecho Social, 16 y 17 de febrero de 2017 (disponible en http:// www.iuslabor.org/jornades-i-seminaris/ponencies/any-2017/, documento consultado el 22 de abril de 2017).
} 
Y todo ello, siempre teniendo en consideración, como he expuesto y defendido en muchas ocasiones, que los debates sobre las sentencias del TJUE, que han girado principalmente sobre el derecho a indemnización de los trabajadores interinos en concreto y de los trabajadores temporales más en general, no nos impida ver el que a mi parecer es el más importante, el de la calidad y estabilidad en el empleo. Y en este punto, no sólo es necesaria una reforma laboral sino también cambios importantes en el modelo productivo de nuestro país. Aquí está, creo, la verdadera apuesta de cambio.

\section{Estudio de la jurisprudencia del TJUE. Sentencias dictadas el 14 de septiembre de 2016}

\subsection{Nombramiento de personal estatutario temporal eventual en el ámbito sanitario público. Sentencia del TJUE de 14 de septiembre de 2016 (asunto C-16/15)}

El TJUE procede en primer lugar al estudio de la normativa europea e interna del Estado que sea de aplicación. Dado que el conflicto versa sobre la interpretación de tres cláusulas, números 3, 4 y 5, del Acuerdo marco sobre el trabajo de duración determinada recogido en el anexo de la Directiva 1999/70/ CE de 28 de junio de 1999, recuerda cuál es el objeto de la Directiva («aplicar el acuerdo marco»), algunos apartados $(6,7$ y 8$)$ de las consideraciones generales del acuerdo marco previas a sus cláusulas, y las cláusulas 2, 3, 4 y 5, interesándome destacar ahora que el acuerdo se aplica a trabajadores «con contrato de trabajo o relación laborali, que el concepto de trabajador con contrato de duración determinada se refiere a "un trabajador con un contrato de trabajo o una relación laborali, y que el apartado 1 de la cláusula 5 se refiere a la regulación de las medidas que deben adoptar los Estados miembros destinadas a evitar la utilización abusiva "de contratos o relaciones laborales de duración determinada». Subrayo que el acuerdo marco no sólo se refiere a la contratación laboral temporal, sino también a otras relaciones laborales que, lógicamente, serán reguladas por otra normativa, pero a las que los firmantes del acuerdo marco, y posteriormente la Directiva, acuerdan conceder los mismos derechos en punto a la estabilidad en el empleo cuando la prestación laboral se desarrolla al margen de la legalidad.

En segundo término, el TJUE procede al estudio de la normativa interna española; en primer lugar, el art. 9 de la Ley 55/2003; a continuación, la normativa laboral propiamente dicha, es decir la LET y más concretamente su art. 15.3, que establece la presunción de la consideración de indefinidos de los contratos temporales que se celebren en fraude de ley, y el art. 49.1.c) regulador de la indemnización de determinados contratos de duración determinada 
en el momento de su finalización, así como también el Real Decreto 2720/1990 de 18 de noviembre, que desarrolla el art. 15 de la LET, mencionando que el art. 3, regulador del contrato eventual «está pensado para dar respuesta a necesidades coyunturales».

El TJUE procede, al entrar en la resolución jurídica del conflicto, al examen de las cuestiones prejudiciales primera y tercera, es decir a determinar si la cláusula 5 del acuerdo marco se opone a una normativa como la del art. 9 de la Ley $55 / 2003$, porque la norma interna no daría respuesta favorable a la necesidad de justificar la temporalidad de una prestación laboral «por causas objetivas». A partir de aquí, el TJUE recuerda los ejes principales de su consolidada doctrina sobre cómo deben interpretarse algunas cláusulas del acuerdo marco. La más relevante a mi parecer, es que el acuerdo engloba a todos los trabajadores, «sin establecer diferencias en función del carácter público o privado del empleador para el que trabajan y ello independientemente de la calificación de su contrato en Derecho interno». El acuerdo no excluye ningún sector particular, por lo que, ya respondiendo a la cuestión prejudicial planteada, «un trabajador como la demandante en el litigio principal, que presta servicios como enfermera y forma parte del personal estatutario temporal eventual de un servicio público de salud, está incluido en (su) ámbito de aplicación».

EL TJUE repasa su amplia y consolidada doctrina sobre la interpretación del apartado 1 de la cláusula 5, que tiene por finalidad fijar unas reglas generales, y de aplicación concreta por parte de cada Estado en los términos que estime más oportunos, para evitar que una persona trabajadora se vea afectada por una sucesión injustificada de contratos temporales, persiguiendo la Directiva «evitar la precarización de los asalariados", en cuanto que la protección de cualquier persona trabajadora debe ir dirigida a garantizar su estabilidad en el empleo, de tal manera que los contratos de duración determinada «sólo pueden responder simultáneamente a las necesidad de los empleadores y los trabajadores en ciertas circunstancias» De ahí que delimite con claridad la obligación de que existan «razones objetivas» (como la enumeradas en la propia cláusula) para justificar la formalización de "contratos o relaciones laborales» de duración determinada. En suma, cada Estado tiene un amplio margen para elegir los medios que considere oportuno para alcanzar el resultado perseguido por la Directiva, de tal manera que las decisiones normativas adoptadas no deben, ni pueden, poner en peligro «el efecto útil» del acuerdo, adoptando además medidas adecuadas para garantizar la plena eficacia de las normas protectoras, medidas que deben ser "proporcionadas, efectivas y disuasorias" para garantizar la plena efectividad de la regulación legal.

Tras este amplio recordatorio de la doctrina del TJUE sobre la protección de quienes trabajan en virtud de la existencia de un contrato o relación laboral de duración determinada, el tribunal también recuerda que la interpretación del ordenamiento jurídico interno es competencia de los tribunales de cada Estado, 
por lo que será el juzgado remitente de la cuestión prejudicial quien deberá valorar si las medidas existentes en el derecho español, en el caso concreto enjuiciado constituyen «una medida apropiada para prevenir y, en su caso, sancionar la utilización abusiva de sucesivos contratos o relaciones laborales de duración determinadd», sin perjuicio de poderse facilitar por parte del TJUE «precisiones destinadas a orientar al órgano jurisdiccional nacional en su apreciación».

Tales precisiones, y yo diría que algo más, consistirán en el litigio en cuestión, en comprobar

si las disposiciones de la norma nacional controvertida en el litigio principal, que permiten la renovación de nombramientos de duración determinada en el ámbito de los servicios de salud, pueden constituir medidas enunciadas en la cláusula 5, apartado 1, del Acuerdo marco, y, más concretamente, razones objetivas que justifican la renovación de contratos o de relaciones laborales de duración determinada.

Sigue recordando su doctrina el TJUE, cual es que el concepto de razón o causa objetiva «se refiere a las circunstancias especificas y concretas que caracterizan una determinada actividad y que, por tanto, pueden justificar en ese contexto particular la utilización sucesiva de contratos de trabajo de duración determinada», y que tales circunstancias "pueden tener su origen, en particular, en la especial naturaleza de las tareas para cuya realización se celebran tales contratos y en las caracteristicas inherentes a las mismas o, eventualmente, en la persecución de un objetivo legitimo de politica social por parte de un Estado miembro». Ahora bien, no se ajusta a esos requisitos una disposición nacional que se limite a autorizar «de manera general y abstracta, a través de una norma legal o reglamentaria, la utilización de sucesivos contratos de trabajo de duración determinada», porque sería un cumplimiento meramente formal pero en absoluto real del acuerdo, ya que no permitiría saber si en efecto existe esa razón o causa objetiva, y en consecuencia entrañaría «un riesgo real de dar lugar a una utilización abusiva de este tipo de contratos», por lo que no sería en absoluto compatible "ni con el objetivo ni con el efecto útil del Acuerdo marco".

Tras este largo, extenso y detallado recordatorio de las notas principales de su doctrina en materia de protección de las personas con contrato o relación laboral de duración determinada, el TJUE pasa revista al contenido del art. 9.3 del Estatuto marco, concluyendo que sí limita la utilización de una prestación laboral (la sentencia ya utiliza el término contrato en el apartado 43) a casos en principios debidamente objetivos y que responden a necesidades provisionales, por lo que, en principio, cumple con el requisito antes señalado de «no establecer una autorización general y abstracta para utilizar sucesivos contratos de duración determinada».

Las razones del art. 9.3 pueden entenderse razonable en el marco de un sector de actividad, sanidad y más en concreto la pública, en el que existe una am- 
plia rotación del personal por muy diversos motivos, y el legislador tiene un margen de maniobra para regular esa actividad laboral de duración determinada a fin y efecto de garantizar «la adecuación constante entre el personal sanitario y el número de pacientes. Pero esa flexibilidad que acepta el TJUE decae, desaparece y por tanto no es aceptada cuando, tal como dispone la normativa española, los «nombramientos de duración determinada» (terminología ahora utilizada correctamente) pueden renovarse "para desempeñar de modo permanente y estable funciones de los servicios de salud incluidas en la actividad normal del personal estatutario fijo». De aceptarse tal posibilidad se iría frontalmente en contra de aquello que es la finalidad del acuerdo marco, es decir «que los contratos de trabajo de duración indefinida constituyen la forma más común de relación laborali, y sin cuestionar en modo alguno que «los contratos de duración determinada sean característicos del empleo en algunos sectores o para determinadas ocupaciones y actividades».

La ayuda o "precisiones» que puede realizar el TJUE para facilitar la tarea del juzgado interno van a ir a mi parecer un paso más allá en cuanto que el TJUE deduce de los datos facilitados en el auto de remisión de la cuestión prejudicial que los sucesivos nombramientos de la recurrente como personal estatutario temporal eventual «no parece responder a meras necesidades temporales del empleadon, basándose, y de ahí la importancia de una buena motivación y fundamentación del auto de planteamiento de la cuestión prejudicial, que el juzgador español ha aportado datos que ponen de manifiesto la muy elevada precariedad de las personas trabajadoras en el sector sanitario público, siendo muy relevantes los datos recogidos en el apartado 51, que estaban expuesto en el auto del juzgador interno, en el que

califica de "mal endémico» la cobertura de puestos en el sector de los servicios de salud mediante nombramientos de personal estatutario temporal y que considera que alrededor del $2 \%$ de las 50000 plazas de plantilla de personal facultativo y sanitario de la Comunidad de Madrid están ocupadas por personal con nombramientos de carácter temporal, llegando en algunos casos extremos a rebasar los 15 años de prestación ininterrumpida de servicios, con una duración media de entre 5 y 6 años.

Por todo ello, el TJUE llega a la conclusión de que la normativa europea se opone a que una norma nacional como el art. 9.3 de la Ley 55/2003 introduzca tal flexibilidad en los nombramientos de duración determinada que en la práctica los mismos se utilicen para cubrir puestos de trabajo que en realidad deberían estar ocupados por personal estable, en cuanto que resuelven necesidades que «son permanentes $y$ estables».

¿Qué ocurre con el margen de discrecionalidad otorgado por el art. 9 a la Administración para crear puestos de trabajo estructurales cuando se comprueba que hay determinadas renovaciones temporales de nombramientos de duración determinada en un determinado lapso de tiempo? Dicha creación puede ser una 
buena herramienta para luchar contra la utilización abusiva de contratos temporales y así lo reconoce el TJUE, siempre y cuando el tránsito desde una causa o razón objetiva que posibilita una prestación laboral temporal hasta la creación de dicho puesto de trabajo estructural se ajuste a las exigencias del acuerdo marco. Pues bien, de la redacción del art. 9.3, y de los datos facilitados en el auto de remisión de la cuestión prejudicial, el TJUE concluye que no existe ninguna obligación para la administración sanitaria española de la creación de tales puestos de trabajo estructurales con los que debería darse por finiquitada el nombramiento de personal laboral temporal eventual, y ello es así porque aunque puedan crearse, la norma posibilita que sean ocupados por personal estatutario temporal interino, sin límite de duración ni de número de posibles renovaciones, por lo que "la situación de precariedad de los trabajadores se convierte en permanente». Sería contrario al acuerdo marco un texto normativo, como el español, que posibilita los nombramientos de duración determinada, con mucha flexibilidad, para cubrir puestos de trabajo permanentes y estables, cuando en el Estado al que pertenece el juzgador existe, debidamente constatado, «un déficit estructural de puestos de personal fijo» en la administración pública sanitaria.

Sentada doctrina sobre el núcleo duro y relevante de las cuestiones planteadas por el juzgador, la Sala aborda la segunda cuestión prejudicial, esto es si la cláusula quinta se opone a una norma como la española, de 2013, que obliga a finalizar la relación de servicio en la fecha prevista inicialmente por el nombramiento, y la pertinente liquidación de haberes, aun cuando sin solución prácticamente de continuidad se lleve a cabo un nombramiento para seguir desempeñando la misma actividad. Es ciertamente, y coincido con el tribunal, una cuestión muy concreta que no encontrará respuesta especifica en el acuerdo marco, en cuanto que el mismo fija criterios generales de actuación para todos los Estados y deja un amplio margen de actuación para que estos lo cumplan en los términos que estimen más adecuados, siempre y cuando se evite la discriminación y el trato abusivo hacia las personas que tienen contrato o relación laboral de duración determinada. Deberá ser el juzgador nacional el que habrá de comprobar si ello es así o no, en el bien entendido, y me parece muy importante destacarlo que sería contrario al acuerdo marco, por verse completamente privado de su objeto, «si el mero hecho de que una relación laboral se considere nueva en Derecho nacional pudiera constituir una "razón objetiva», en el sentido de dicha cláusula, que permitiera autorizar una renovación de un contrato de trabajo de duración determinada».

La última cuestión prejudicial analizada por el TJUE es la cuarta planteada por el juzgador español, y responde a la posible existencia de diferencia de trato no justificada, y por ello discriminatoria, entre el personal «con nombramiento estatutario temporal» y el personal "con contrato de duración determinada», ya que los segundos, en los términos dispuestos en el art. 49.1.c) de la LET, tienen derecho a una indemnización por finalización de contrato, mientras que no recibe 
ninguna indemnización el personal estatutario temporal al finalizar el período fijado en su nombramiento.

El TJUE se declarará incompetente para responder esta cuestión tras el estudio de la cláusula 4 del acuerdo marco y de su propia doctrina, y concluir que no se da el supuesto que permitiría su conocimiento.

¿Cuál es su argumentación? Que el principio de no discriminación ha sido aplicado en cuanto se ha debatido sobre las diferencias de trato entre trabajadores con contratos temporales e indefinidos «que se encuentren en situación comparable», mientras que no está contemplado para debatir sobre las diferencias entre personal trabajador en razón de su carácter funcionarial o laboral, y en ambos casos tratándose de situaciones estatutarias o contractuales de duración determinada. Para el TJUE sólo sería posible entrar a conocer de un litigio, por ser de aplicación la cláusula 4 del acuerdo marco, cuando existiera una diferencia de trato entre personal estatutario con relación de servicios por tiempo indefinido y personal estatutario con nombramiento temporal y que realizaran «un trabajo comparable», diferencia consistente en que el primero grupo percibiera una indemnización al finalizar su prestación y no el segundo, pero ello no ocurre, y tal como afirma el TJUE

en la medida en que ningún elemento de los autos en poder del Tribunal de Justicia deja ver que en el litigio principal exista una diferencia de trato entre el personal estatutario temporal eventual y el personal estatutario fijo, la diferencia de trato objeto de la cuarta cuestión prejudicial planteada por el juzgado remitente no está comprendida en el ámbito de aplicación del Derecho de la Unión.

En definitiva, la sentencia lleva a plantear la necesidad de resolver una situación laboral fáctica en la sanidad pública en la que el grado de incumplimiento de la normativa europea se ha demostrado de forma clara y fehaciente, y que requerirá a mi parecer que se adopten las medidas normativas oportunas, tratando de buscar fórmulas jurídicas que permitan que el personal con nombramiento temporal que en realidad no es tal por cubrir necesidades permanentes y estables puede tener mayor estabilidad en su vida laboral, con acercamiento a la situación del personal indefinido no fijo en el ámbito laboral en sentido estricto.

\section{2. ¿Nombramientos indefinidos no fijos? Sentencia del TJUE de 14 de septiembre de 2016 (asuntos C-184/15 y C-197/15)}

La sentencia se dicta, sin conclusiones del abogado general, para dar respuesta a dos peticiones de decisión prejudicial planteadas por dos autos de la misma fecha, 9 de marzo de 2015, dictados por la Sala de lo ContenciosoAdministrativo del Tribunal Superior de Justicia del País Vasco. Los dos litigios que merecen la atención especial del TSJ vasco se refieren a los pro- 
blemas derivados de nombramientos y relación de servicios de duración determinada que son extinguidos por decisión de la Administración y para los que el TSJ plantea que la normativa española podría no tener una protección adecuada frente a la actuación abusiva de aquella, siendo así que se vulneraría el acuerdo marco recogido en la Directiva 1999/70/CE que establece el principio de igualdad de trato para los trabajadores con contratos de duración determinada en relación con los trabajadores con contrato indefinido que puedan ser comparables. En el primer caso el empleador es el servicio vasco de salud, y en el segundo el ayuntamiento de Vitoria. En efecto, según puede leerse en el apartado 2 de la sentencia, el primer conflicto versa «en relación con las renovaciones de su nombramiento de duración determinada y con la legalidad de la resolución por la que se puso fin a dicho nombramiento", mientras que el segundo trata «en relación con la calificación jurídica de su relación de servicio y con la legalidad de la resolución mediante la que finalizó dicha relación».

En el asunto C-184/15, se trata de una persona que presta sus servicios para el servicio vasco de salud con un nombramiento como personal estatutario temporal eventual de fecha 2 de febrero de 2010 y prorrogado en trece ocasiones hasta su finalización el 1 de octubre de 2012. El nombramiento se produjo, al amparo del art. 9.3 del Estatuto marco del personal estatutario de los servicios médicos de salud (Ley 55/2003), para prestar servicios "de naturaleza temporal, coyuntural o extraordinaria", mientras que en las prórrogas sólo hay una referencia a "las necesidades del servicio». Contra la decisión de dar por finalizada la relación estatutaria, la trabajadora (y utilizo el término en sentido material y no formal, incluyendo a toda persona que desarrolla una actividad remunerada para otra y con independencia de que esté regulada o no en la Ley del Estatuto de los trabajadores), interpuso recurso contencioso-administrativo, desestimado por el juzgado C-A núm. 6 de Bilbao, y posteriormente recurso ante el TSJ vasco, por considerar que los tres supuestos recogidos en el citado precepto «no pueden fundirse en una categoría global para motivar la existencia de un nombramiento de duración determinada».

En el asunto C-197/15, la relación del trabajador con el ayuntamiento vitoriano se inició el 1 de diciembre de 1993 mediante la formalización de un contrato de duración determinada, al que siguió dos años más tarde un nuevo contrato temporal. La relación jurídica del trabajador con el ayuntamiento pasó a ser de funcionario interino por nombramiento efectuado el 22 de enero de 1998, para llevar a cabo la misma tarea que la asignada en el segundo contrato y hasta la finalización del programa. Desde entonces, y hasta catorce años más tarde, el trabajador siguió prestando sus servicios, notificando la administración su cese con efectos de 31 de diciembre de 2012, justificado (vid apartado 22) en que el programa "habia sido ejecutado en su totalidad y que el contexto actual de crisis imponia la reducción de gastos de las Administraciones Públicas». Al igual que 
en el primer supuesto, el recurso contencioso-administrativo fue desestimado en instancia, interponiendo posteriormente recurso de apelación ante el TSJ vasco en el que puso de manifiesto que el juzgado no se había pronunciado sobre la naturaleza jurídica de su relación con la administración, es decir si era de carácter laboral o administrativa.

¿Cuáles son las "precisiones» que realiza el TJUE, con respecto a su ya consolidada doctrina, en los casos ahora enjuiciados? Tras recordar el contenido del auto del TSJ y subrayar la diferente protección según la naturaleza jurídica de la relación que vincula al trabajador con la administración, el TJUE concluye que si, tras las pertinentes averiguaciones, el tribunal interno formara su convicción de no existir una medida que permita evitar y que sancione la actuación abusiva del empleador con quienes prestan sus servicios en régimen de derecho administrativo "tal situación podría menoscabar el objetivo y el efecto útil del acuerdo", y por consiguiente debería adoptar las medidas adecuadas para lograr dicho efecto útil, en cuanto que, con reiteración de su doctrina, el TJUE recuerda que la obligación de alcanzar un resultado previsto por una Directiva se impone a todas las autoridades del Estado, "incluidas, en el marco de sus competencias, las autoridades judiciales».

Es aquí cuando llega la respuesta del TJUE que debe merecer especial atención, dado que concreta la protección que deben tener todas las personas que trabajan en régimen de derecho administrativo en una Administración que actúa de manera abusiva con sus nombramientos como personal temporal eventual o funcionario interino: si no hay ninguna medida (y así es) equivalente y eficaz de protección,

la asimilación de dicho personal con relaciones de servicio de duración determinada a los trabajadores indefinidos no fijos, con arreglo a la jurisprudencia nacional existente, podría ser una medida apta para sancionar la utilización abusiva de los contratos de trabajo de duración determinada y eliminar las consecuencias de la infracción de lo dispuesto en el Acuerdo marco.

Con respecto a la tercera cuestión prejudicial, únicamente aplicable al caso del trabajador que prestaba sus servicios para el ayuntamiento de Vitoria, el TJUE recuerda que la resolución de litigios y quejas que resulten de la aplicación del acuerdo marco debe ajustarse a la normativa, legal y convencional, regulada en el ámbito de cada Estado, debiéndose adoptar las medidas oportunas para garantizar la plena eficacia de aquellas normas, y que tales medidas «deben ser conformes con los principios de equivalencia y efectividad». En el marco normativo español vigente, el TJUE constata que el tribunal que conoce del litigio en el que debe resolverse si la Administración ha actuado de forma abusiva mediante sucesivos nombramiento de duración determinada sin causa o razón debidamente justificada, "no puede pronunciarse sobre una posible solicitud 
de reparación del daño sufrido por el empleado afectado». Para el TJUE, en otra importante manifestación a la que habrá que prestar mucha atención por los cambios normativos que pudiera implicar en la jurisdicción contencioso-administrativa,

la obligación que incumbe al trabajador con contrato de duración determinada de ejercitar una nueva acción, en su caso ante un tribunal diferente, para determinar la sanción apropiada cuando una autoridad judicial ha declarado la existencia de utilización abusiva de sucesivos contratos de trabajo de duración determinada no muestra ser conforme con el principio de efectividad, en la medida en que de ella se derivan necesariamente para dicho trabajador inconvenientes procesales, en forma, en particular, de costes, de duración y de normativa de representación procesal,

por lo que concluye que la normativa comunitaria se opone a las normas procesales nacionales que obliguen a ello.

En definitiva, esta importante sentencia confirma una vez más la importancia de la jurisprudencia del TJUE en la regulación de las relaciones de trabajo en el marco nacional español, ya estén sometidos a régimen laboral o a régimen administrativo.

\subsection{Sobre la protección de los trabajadores temporales en caso de extinción contractual. Sentencia del TJUE de 14 de septiembre de 2016 (asunto C-596/14)}

\subsubsection{El supuesto fáctico}

Pasemos al estudio del caso, a partir de los datos disponibles en la sentencia. La relación contractual laboral entre la trabajadora y el Ministerio de Defensa (estamos, en consecuencia, en el ámbito público) se inicia en febrero de 2003, y se nos informa que formalizó varios contratos de interinidad hasta el 17 de agosto de 2005, fecha en la que formalizó el que mantendría su vigencia hasta el 30 de septiembre de 2012, encontrando su fundamento jurídico en la sustitución de una trabajadora fija de plantilla que se encontraba en situación de excedencia, con reserva de puesto de trabajo, por ocupación de cargo de representante sindical. La extinción de la reserva de puesto de trabajo, que conllevó el cese de la trabajadora interina, se produjo con arreglo a lo dispuesto en el Real Decreto-Ley 20/2012 de 13 de julio, de medidas para garantizar la estabilidad presupuestaria y de fomento de la competitividad.

Es decir, estamos en presencia de una relación laboral temporal casi indefinida, y no lo digo ahora desde el plano jurídico en sentido estricto sino desde la constatación de que nueve años y medio de antigüedad en una empresa es un período muy dilatado en la realidad actual de las relaciones laborales, y calificar 
la relación de temporal lleva necesariamente a pensar que bajo la cobertura jurídica se encubre una realidad que requiere de una modificación normativa que la corrija. En realidad, creo que la sentencia pone blanco sobre negro la existencia de una práctica consistente en la utilización de la normativa sobre contratación temporal para cubrir necesidades productivas permanentes.

En conclusión, la trabajadora interina, que me atrevería a calificar como «interina permanente», estuvo en dicha situación contractual laboral, al amparo de diferentes contratos suscritos con el Ministerio de Defensa, nueve ańos y medio. Más allá de la respuesta concreta al litigio planteado, cabe plantearse la necesidad de una modificación legislativa que ponga fin a esta situación de estabilidad interina (permítanme los juegos de palabras) y devuelvan la razón de ser de esta modalidad contractual a los supuestos concretos, tasados y limitados en el tiempo, muy en especial en el sector público.

\subsubsection{La respuesta del TJUE. Análisis crítico}

Analicemos a continuación las respuestas del TJUE a las cuestiones prejudiciales planteadas por el TSJ de Madrid; respuestas que sólo serán dos, en cuanto que en primer lugar sí responderá por separado a la primera planteada, esto es si la cláusula 4.1 del Acuerdo marco debe interpretarse de tal manera que el concepto de condiciones de trabajo incluya «la indemnización que un empresario está obligado a abonar a un trabajador como consecuencia de la finalización de su contrato de duración determinada», mientras que más adelante responderá de forma conjunta a las preguntas segunda, tercera y cuarta.

$\mathrm{Al}$ igual que en ocasiones anteriores en que el TJUE ha debido pronunciarse sobre la interpretación de algunas cláusulas del Acuerdo Marco, formula unas consideraciones generales previas para destacar la importancia de su contenido en orden a garantizar la protección de los trabajadores con contrato de duración determinada y la evitación de actuaciones discriminatorias hacia ellos basadas únicamente en la duración del vínculo contractual, no siendo contraria a derecho una diferencia de trato con los trabajadores indefinidos que esté basada en una causa o razón objetiva, dejando, recuerdo ahora, un amplio margen de libertad a los Estados miembros para que adopten las medidas que consideren más adecuadas para la incorporación de la Directiva al ordenamiento jurídico interno.

Estas consideraciones se recogen en los apartados 25 y 26 de la sentencia, con apoyo de anteriores resoluciones en las que el TJUE se ha manifestado en los mismos términos. Pero sin duda es especialmente relevante, por la importancia que ello tiene en orden a defender la aplicación de la sentencia a las relaciones entre particulares, es el recordatorio efectuado en el apartado 27 de que la cláusula 4 expresa "un principio de Derecho Social de la Unión que no puede ser interpretado de manera restrictiva». En una anterior sentencia, también de in- 
El Tribunal de Justicia de la Unión Europea y el impacto de Su reciente jurisprudencia en la Regulación DE LA CONTRATACIÓN TEMPORAL EN ESPAÑA Y EL DERECHO A INDEMNIZACIÓN POR EXTINCIÓN DEL CONTRATO

dudable importancia para el derecho español, caso Del Cerro Alonso (asunto C-307/05), el TJUE ya puso de manifiesto que

habida cuenta de la importancia de los principios de igualdad de trato y de no discriminación, que forman parte de los principios generales del Derecho comunitario, a las disposiciones previstas por la Directiva 1999/70 y el Acuerdo marco a efectos de garantizar que los trabajadores con un contrato de duración determinada disfruten de las mismas ventajas que los trabajadores por tiempo indefinido comparables, salvo que esté justificado un trato diferenciado por razones objetivas, debe reconocérseles un alcance general, dado que constituyen normas de Derecho social comunitario de especial importancia de las que debe disfrutar todo trabajador, al ser disposiciones protectoras mínimas.

El TJUE incluirá la indemnización que debe ser abonada a un trabajador a la finalización de su contrato en el concepto de condiciones de trabajo, y lo hará partiendo de su criterio, defendido ya en anteriores sentencias, que aquello decisivo "para determinar si una medida está incluida en este concepto es precisamente el del empleo, es decir, la relación laboral entre un trabajador y su empresarion. En anteriores resoluciones judiciales, el TJUE ya había incluido, a los efectos de garantizar la igualdad de trato a los trabajadores temporales, a los trienios, «que constituyen uno de los elementos retributivos que deben concederse a un trabajador con contrato de duración determinada del mismo modo que a un trabajador con contrato de duración indefinida», así como también "las normas relativas a la determinación del plazo de preaviso aplicable en caso de finalización de los contratos de duración determinada», y es ahora del parecer que dichas tesis "pueden ser integramente traspuestas a una indemnización como la controvertida en el litigio principali, en cuanto que la indemnización se concede al trabajador por razón de la finalización del contrato de trabajo que le vincula a su empresario, y es por ello que está englobada dentro de la relación laboral empresario-trabajador y debe estar incluida en el concepto de «condiciones de trabajo» enunciado en la cláusula 4.1 del acuerdo marco.

En cualquier caso, la tesis del TJUE en la sentencia objeto de comentario nos obliga a incorporar la indemnización entre las condiciones de trabajo, lo que tendrá importancia relevante, como veremos más adelante, a la hora de reconocer el derecho a indemnización a los contratos de trabajo de duración determinada, y a su cuantía, a su finalización.

Pasa a continuación el TJUE a responder conjuntamente a las cuestiones prejudiciales segunda, tercera y cuarta. Dicho sea incidentalmente, no tengo muy claro cuál era la finalidad del TSJ al plantearlas, si saber si un interino debe cobrar la misma indemnización que un trabajador con contrato indefinido comparable, o bien la misma que cobra otro trabajador temporal contratado por obra o servicio o por necesidades de la producción, y puestos a manifestar mi parecer me inclinaría más por la segunda, pero es obvio que el TJUE no podía responder a dicha cuestión en atención a los términos en que está redactada 
la cláusula 4.1 del acuerdo marco. De ahí que el TJUE recuerde en sus apartados 37 y 38 de la sentencia que

el principio de no discriminación se ha aplicado y concretado mediante el Acuerdo marco únicamente en lo que respecta a las diferencias de trato entre trabajadores con contrato de duración determinada y trabajadores con contratos por tiempo indefinido que se encuentren en una situación comparable,

por lo que

las posibles diferencias de trato entre determinadas categorías de personal con contrato de duración determinada, como la que menciona el tribunal remitente en la cuarta cuestión prejudicial, no están incluidas en el ámbito de aplicación del principio de no discriminación consagrado por dicho Acuerdo marco.

Por ello, el fallo de la sentencia sí cierra la puerta al debate de saber si los interinos tienen derecho a indemnización a la finalización de su contrato, con respuesta positiva sin duda alguna, y la mantiene abierta para determinar si aquella debe ser idéntica a la de un trabajador indefinido comparable que vea extinguido su contrato por causas objetivas, es decir 20 días de salario por año de servicio, o bien ser la de 12 días que se abona actualmente a la finalización de otros contratos de duración determinada, y al mismo tiempo deja abierta la puerta al debate de cuál ha de ser la indemnización que perciban los que ahora la tienen fijada en doce días.

Nuevamente, y al igual que al responder a la primera cuestión, el TJUE formula unas consideraciones generales previas sobre el contenido de la cláusula 4.1 y el principio de no discriminación entre trabajadores con contrato o relación laboral de duración indefinida y aquellos cuyo contrato o relación laboral es de duración determinada. La tesis central del TJUE, y sobre la que pivotará posteriormente su respuesta al caso De Diego Porras, es que las situaciones comparables no pueden tratarse de forma diferente, salvo que exista una causa o razón objetiva que lo posibilite, es decir que dicha diferencia de trato «esté objetivamente justificada». Por consiguiente, la primera pregunta que debemos hacernos, y que en efecto también se hace el TJUE, es si el marco normativo espańol establece una diferencia de trato entre trabajadores interinos y trabajadores indefinidos en el momento de la extinción de sus contratos, y ya sabemos que la respuesta es afirmativa: los primeros no perciben ninguna indemnización, y tal como recuerda el TJUE, «con independencia de la duración de los servicios prestados» (y recordemos que en el caso enjuiciado la interinidad se prolongó durante nueve años y medio, y que las tareas de la trabajadora interina, a la luz de la información disponible, eras sustancialmente idénticas o comparables a las de otros compañeros y compañeras que prestaran la misma actividad pero con relación contractual estable), mientras que los indefinidos sí la perciben cuando hay 
una causa de extinción de las previstas en el art. 52 de la LET, y ello con independencia de la mayor o menor duración de su contrato.

Una vez constatada la diferencia de trato, ha de comprobarse si las situaciones controvertidas pueden ser comparables a los efectos de aplicación del acuerdo marco, y en un segundo momento debe comprobarse si existe «una posible justificación objetiva» que permita la diferencia de trato en el supuesto, repito, de encontrarnos ante situaciones comparables.

¿Cuál es el tertium comparationis del TJUE? ¿Estamos en presencia de un trabajo «idéntico o similar» entre los trabajadores indefinidos y los trabajadores interinos (y temporales en general)? El TJUE acude a las cláusulas 3.2 y 4.1 del Acuerdo marco, que listan (en modo alguno, a mi parecer, de forma exhaustiva) un conjunto de factores que permitan determinar la existencia o no de tal comparabilidad, como son «la naturaleza del trabajo, los requisitos de formación y las condiciones laborales", que ya ha tomado en consideración en anteriores resoluciones judiciales de las que se deja debida constancia en el apartado 40.

¿Estamos o no ante situaciones diferentes? Si la respuesta es afirmativa, la diferencia estará objetivamente justificada, y ello ocurriría cuando «las funciones desempeñadas por un trabajador como la recurrente en el litigio principal en el marco de los diferentes contratos de duración determinada no correspondieran a las de los trabajadores fijos», ya que de no existir tal diferencia objetiva, el trato dispensado a los trabajadores temporales respecto a la indemnización a la finalización de su contrato ( 0 euro para los interinos, 12 día de salario por año de servicios para otras modalidades contractuales) sería contrario a la normativa comunitaria, más exactamente a la cláusula 4 del acuerdo marco.

Aunque el TJUE recuerda que corresponde al tribunal nacional determinar si existió esa situación de comparabilidad durante la vigencia de la relación contractual de la Sra. De Diego Porras con el empleador Ministerio de Defensa, con respecto a la de un trabajador con contrato indefinido durante el mismo período de tiempo, ya le da prácticamente la respuesta afirmativa, algo que tendrá importancia determinante en la sentencia dictada por la Sala de lo Social del Tribunal Superior de Justicia de Madrid el 5 de octubre al conocer nuevamente del litigio, al afirmar que "es preciso no obstante señalar que, en el caso de autos, se desprende de los autos obrantes en poder del Tribunal de Justicia que la recurrente en el litigio principal efectuaba un trabajo análogo o idéntico al de un trabajador fijo», por lo que se trata de una situación que puede ser comparable a los efectos de la aplicación del principio de no discriminación.

El TJUE lo justifica por la duración de su último contrato de interinidad y las tareas desarrolladas, aun cuando creo que esta tesis es perfectamente extrapolable a los varios contratos de interinidad que la trabajadora había suscrito con 
la misma empleadora (Administración Pública) con anterioridad. Tal como expone en el apartado 43 ,

... el propio hecho de que la mencionada recurrente ocupara durante siete años consecutivos el mismo puesto de una trabajadora en situación de dispensa de obligaciones laborales vinculada a su condición sindical no sólo permite concluir que la interesada cumplía los requisitos de formación para acceder al puesto de trabajo de que se trata, sino también que efectuaba el mismo trabajo que la persona a la que reemplazó de forma permanente durante este largo período de tiempo, aplicándosele también las mismas condiciones de trabajo.

Afirmada la existencia de situaciones comparables, la diferencia sólo estará justificada si existe una razón, causa o justificación objetiva que la permita, y a averiguar su existencia o no se dirige el análisis y razonamiento del TJUE en los apartados posteriores de la sentencia. En primer lugar, acudiendo a su doctrina general sobre el concepto de «razones objetivas», para lo que se requiere que la desigualdad de trato apreciada

esté justificada por la existencia de elementos precisos y concretos, que caracterizan la condición de trabajo de que se trata, en el contexto específico en que se enmarca y con arreglo a criterios objetivos y transparentes, a fin de verificar si dicha desigualdad responde a una necesidad auténtica, si permite alcanzar el objetivo perseguido y si resulta indispensable al efecto,

resaltando, con amplio apoyo en resoluciones judiciales dictadas con anterioridad que

tales elementos pueden tener su origen, en particular, en la especial naturaleza de las tareas para cuya realización se celebran los contratos de duración determinada y en las características inherentes a las mismas o, eventualmente, en la persecución de un objetivo legítimo de política social por parte de un Estado miembro.

Tal tesis general lleva a concluir, en la misma línea que la defendida en anteriores sentencias, que la diferencia de trato no estará en modo alguno justificada por el simple hecho de que se encuentre recogida en «una norma nacional general y abstracta como una ley o un convenio colectivon; es obvio que en el caso enjuiciado así ocurre, ya que la diferencia está prevista con carácter general en la LET, diferenciando por una parte a los trabajadores indefinidos, por otra a los trabajadores temporales con contratos para obra o servicio, o por necesidades de la producción, y por una tercera a los trabajadores interinos (y no sólo a ellos, sino también a los trabajadores con contrato formativo y a los acogidos al contrato indefinido de fomento de empleo y de apoyo a los emprendedores).

La conclusión de todo lo anteriormente expuesto para el TJUE es que no basta la existencia de una norma general abstracta en la que se recoja la diferen- 
cia de trato en punto al percibo de una indemnización por la extinción contractual, ni tampoco la mera naturaleza temporal de la relación (que repito que en muchas ocasiones, y los repertorios jurisprudenciales dan debida cuenta de ello, pueden encubrir auténticas relaciones contractuales de duración indefinida), para poder justificar la diferencia entre trabajadores indefinidos y temporales con respecto al percibo de la indemnización por fin del contrato.

Mucho menos apoyo tiene la "mera naturaleza temporal de la relación» en un caso como el enjuiciado, en el que la duración de la vida laboral de la trabajadora en su empresa ha tenido una antigüedad superior a la de muchos trabajadores indefinidos, pues no es poca cosa en la actualidad tener una antigüedad de nueve ańos y medio. Por ello, es perfectamente comprensible la tesis «adicional» a las consideraciones defendidas con anterioridad por la Sala de que

la alegación basada en la previsibilidad de la finalización del contrato de interinidad no se basa en criterios objetivos y transparentes, siendo así que, en realidad, no sólo tal contrato de interinidad puede perpetuarse, como en la situación de la recurrente en el litigio principal, cuyas relaciones contractuales se extendieron durante un período de más de diez años, sino que además contradice tal alegación el hecho de que, en circunstancias comparables, la normativa nacional pertinente prevea la concesión de una indemnización por finalización del contrato a otras categorías de trabajadores con contrato de duración determinada.

Tesis que, en su segunda parte, refuerza la argumentación de que debe abonarse en todo caso una indemnización a los trabajadores interinos y que puede fortalecer la de quienes defienden que la indemnización debe ser la misma para todos los trabajadores temporales (y aquí se abre otro debate de indudable calado político, cual es la cuantía de la indemnización $)^{3}$.

La doctrina laboralista no parece discrepar en que la sentencia del caso De Diego Porras reconoce el derecho de una trabajadora con contrato de interinidad a no ser discriminada, cuando se produzca la finalización de su contrato, con respecto al trato que se otorgue a un trabajador fijo «comparable», a menos, dice el acuerdo marco objeto de interpretación, que se justifique un trato diferente "por razones objetivas». Insisto en algo que he destacado a lo largo de mi

${ }^{3}$ Por el interés, y la polvareda jurídica y social que ha levantado, que tiene a los efectos de una mejor comprensión de la resolución del caso, y de su impacto sobre las posibles modificaciones de la normativa laboral, reproduzco el segundo apartado del fallo de la sentencia: «La cláusula 4 del Acuerdo marco sobre el trabajo de duración determinada, que figura en el anexo de la Directiva 1999/70, debe interpretarse en el sentido de que se opone a una normativa nacional, como la controvertida en el litigio principal, que deniega cualquier indemnización por finalización de contrato al trabajador con contrato de interinidad, mientras que permite la concesión de tal indemnización, en particular, a los trabajadores fijos comparables. El mero hecho de que este trabajador haya prestado sus servicios en virtud de un contrato de interinidad no puede constituir una razón objetiva que permita justificar la negativa a que dicho trabajador tenga derecho a la mencionada indemnización». 
exposición: la demandante prestó sus servicios como trabajadora interina durante casi diez años, una contratación que tiene muy poco de temporal, aunque pueda ser, y así lo manifiesta el tribunal español que eleva la cuestión prejudicial, plenamente conforme a derecho.

¿Cuándo puede empezar el debate, hasta convertirse en discrepancia? En concreto, en la aplicación de la sentencia a toda la contratación temporal regulada en la normativa laboral española, y no sólo a la contratación interina. Si se acepta la primera tesis, también debería verse modificada la indemnización actual de 12 días y experimentar una subida hasta los 20 días que se abona a un trabajador indefinido que ve extinguido su contrato por causas objetivas. Ya he puesto de manifiesto que hay discrepancias al respecto, y que el debate se centra en qué debe entenderse por causa o razón objetiva que justifica la contratación temporal, y qué debe entenderse por trabajador indefinido comparable, así como también qué reglas tener en consideración para aplicar la comparación.

¿En qué punto sigue, como consecuencia de la discrepancia anterior, el análisis de la sentencia? En la cuantía de la indemnización a percibir por un trabajador interino, postulándose dos tesis perfectamente diferenciadas, la de abono de la misma indemnización que a los restantes temporales, o la que se abona a los trabajadores indefinidos por una extinción objetiva conforme a derecho. Se abre aquí, además, un nuevo frente: ¿todos los contratos de duración determinada deben tener derecho a indemnización a su finalización? Si acudimos a la literalidad de la sentencia, tanto en sus argumentos jurídicos como en su fallo, la respuesta debe ser afirmativa, pero ya he dicho que el parecer no es unánime al respecto.

Volvemos al acuerdo, aunque no se manifieste con tanta claridad que en los supuestos anteriores. Un trabajador interino siempre tiene derecho a indemnización en el actual marco normativo si la contratación es no conforme a derecho, de tal manera que percibiría la misma indemnización (33 días de salario/año) que un trabajador indefinido cuya extinción objetiva o disciplinaria fuera declarada improcedente y la empresa optara por el abono de la indemnización. Conviene dejarlo bien claro porque en el fragor del debate sobre la indemnización debida a un trabajador temporal interino se ha dejado de lado que las extinciones contractuales en España son causales, y que el incumplimiento de la causa, o su no debida justificación, supone la obligación del abono de una indemnización como la indicada más arriba (siempre que la parte empresarial no haya optado por la readmisión del trabajador)

¿Dónde vuelve a situarse el debate, que puede llegar al desacuerdo? En qué debe entenderse por una diferencia de trato justificada "por razones objetivas". No es lo mismo, por ejemplo, un contrato eventual por necesidades de la producción, con plazo estipulado, que una extinción por causas económicas o productivas. Pero en este segundo caso, ¿puede llegar a entenderse que una finalización de un contrato de trabajo interino puede constituir una causa objetiva en 
los mismos términos que el despido de un trabajador indefinido al amparo del art. 52.c) de la Ley del Estatuto de los Trabajadores. Voces autorizadas así lo manifiestan, con argumentos de no poca consideración (y sigue el debate).

¿Hacia dónde intentan algunos llevar sus tesis, y por ello existe un claro desacuerdo con quienes piensan lo contrario? Pues en la afirmación de que la sentencia abre la puerta al mal llamado contrato único. Pero no: todo despido, toda extinción contractual debe estar justificada, y si se quiere descausalizar, que el gobierno denuncie el Convenio núm. 158 de la Organización Internacional del Trabajo. ¡Ah! Sin olvidar la jurisprudencia del Tribunal Constitucional sobre el derecho al trabajo y a la protección contra una extinción injustificada.

Y más aún, en el mismo intento hay quienes defienden que la aplicación de la sentencia pasa por equiparar las indemnizaciones de fijos y temporales, y por ello es posible disminuir la actualmente fijada para los primeros. Craso error jurídico a mi parecer, porque el apartado 3 de la cláusula 8 del acuerdo marco dispone que "La aplicación de las disposiciones del presente Acuerdo no podrá constituir una justificación válida para la reducción del nivel general de protección de los trabajadores en el ámbito cubierto por el presente Acuerdo».

Al final, ¿en qué estamos todos de acuerdo? En que hay que modificar el marco normativo de contratación, aunque aquí se detenga el acuerdo porque quienes creemos que ello pasa por la mayor rigurosidad en la regulación y cumplimiento de la normativa sobre contratación temporal no podemos ni queremos compartir la tesis de quienes creen que un "contrato único o de tutelas crecientes» resolvería por arte de magia todos los problemas de nuestro mercado de trabajo.

\section{Estudio de tres autos dictados por el TJUE (14 y 21 de septiembre de 2016, y 9 de febrero de 2017)}

\subsection{Discriminación del personal docente interino por no poder participar en el plan de evaluación docente. Nota al auto del Tribunal de Justicia de la Unión Europea de 21 de septiembre de 2016 (asunto C-631/15)}

En el caso ahora enjuiciado nos encontramos ante un docente que tiene una antigüedad en la prestación de sus servicios muy superior a las de cinco años requeridos por la normativa autonómica y que puede tener los mismos requisitos de "formación, dedicación al centro o implicación en la consecución de sus objetivos»..., pero no es funcionario de carrera. Para el juzgador, no hay razón objetiva alguna, a la luz de los datos disponibles, que pueda justificar la diferencia de trato simplemente por la naturaleza jurídica de la relación (funcionario de carrera, funcionario interino), y mucho más cuando de la normativa aplicable se deduce que la evaluación positiva que puede alcanzar un docente «en nada va 
ligada a un sistema de ascenso o de progreso profesional, sino que se traduce única y exclusivamente en la obtención de un incentivo económico». Por todo ello, eleva la cuestión prejudicial al TJUE.

El TJUE resuelve mediante auto motivado, al amparo de la posibilidad ofrecida por el art. 99 de su Reglamento de procedimiento Adopta tal decisión porque, como dice textualmente en el apartado 26, "la respuesta a la cuestión prejudicial puede deducirse claramente de la jurisprudencia del Tribunal de Justicia», listando un amplio número de sentencias y autos en que se ha pronunciado en los mismos términos que lo hará en el auto ahora objeto de comentario.

Antes de entrar a resolver la cuestión prejudicial planteada, el TJUE formula unas consideraciones generales previas sobre la Directiva 1999/70/CE y el Acuerdo marco, sustancialmente idénticas a las expuestas en las tres sentencias de 14 de septiembre y que por ello no reitero ahora. Sólo recuerdo la consolidada doctrina del TJUE respecto a que la cláusula 4.1 del Acuerdo marco «expresa un principio de Derecho social de la Unión que no puede ser interpretado de forma restrictiva», siendo «incondicional y suficientemente precisa para que los particulares puedan invocarla frente al Estado ante un juez nacionali. Destaco que, de acuerdo a la consolidada jurisprudencia del TJUE, el funcionario interino con más de 16 años de antigüedad en la prestación de servicios docentes en centros educativos públicos de la comunidad asturiana, "está incluido en el ámbito de aplicación de la Directiva 1999/70 y del Acuerdo marco».

En virtud de la misma jurisprudencia, el TJUE llegará a la conclusión de que la participación en un plan de evaluación docente, y el incentivo económico derivado de la evaluación positiva que puede obtenerse, están incluidos en el concepto de condiciones de trabajo en el sentido de la dispuesto en la cláusula 4.1 del Acuerdo marco, aun cuando nuevamente recuerde que el juzgador nacional remitente el que debe «determinar la naturaleza y los objetivos de las medidas controvertidas».

¿Cómo llega el TJUE a la conclusión de que estamos en presencia de condiciones de trabajo al amparo de la normativa comunitaria? En primer lugar, porque el requisito de la antigüedad, que cumple el funcionario interino, se integra dentro de las relaciones de trabajo entre empresario y trabajador, y en segundo término porque aquello que realmente importa de la evaluación es la obtención de un complemento económico, es decir una mejora económica del salario percibido. Este incentivo, observa el TJUE debe concederse por igual, y por ello como paso previo habrá que habilitar las condiciones para poder solicitarlo, a trabajadores con relación laboral de duración determinada o indefinida, ya que otra interpretación que abone la diferencia de trato incumpliría el objetivo que persigue la normativa comunitaria al reducir «el ámbito de aplicación de la protección contra las discriminaciones otorgada a los trabajadores con contrato de duración determinada». 
Confirmada, pues, la existencia de una condición de trabajo, es el momento de analizar si son comparables las situaciones laborales del personal fijo y personal interino docente, y en el supuesto de que así fuere, y ya adelanto que la respuesta es afirmativa, si existe una causa, razón o justificación objetiva que permita diferenciarlas a los efectos legales. Nuevamente el TJUE acudirá a su consolidada doctrina jurisprudencial para determinar si los funcionarios docentes fijos e interinos desempeñan o realizan una trabajo idéntico o similar y tras volver a recordar que debe ser el juzgador nacional el que se pronuncie si ambos grupos de funcionarios se encuentran en situación comparable, manifiesta con claridad y contundencia que ello es así a su parecer, La redacción del apartado 45 no deja lugar a dudas: no se requieren cualificaciones académicas o experiencias profesionales diferentes; más bien será al contrario, ya que

se desprende de las indicaciones contenidas en el auto de remisión que estas dos categorías de profesores ejercen funciones similares y están sometidos a obligaciones idénticas, en particular en lo que atańe a los criterios aplicados en los planes de evaluación referidos a la formación, a la contribución a los objetivos del centro y a la participación en sus actividades.

Si la comparabilidad queda acreditada en cuanto a las funciones o tareas a desarrollar, la única diferencia que existe entre ambos colectivos es la naturaleza temporal de la relación de servicio, en cuando que el funcionario interino puede ser cesado cuando concurran las circunstancias legales requeridas para que ello sea posible, situación jurídica bien diferente a la del funcionario de carrera y que tiene una plaza en propiedad. ¿Será esta diferencia la causa, razón o justificación objetiva, que posibilita según la normativa comunitaria una diferencia de trato? A ello se apresta a responder el TJUE, y ya adelanto que la respuesta, al igual que en otras sentencias y autos anteriores, es claramente negativa.

Destaco del auto la remisión a la consolidada doctrina de que una diferencia de trato no puede justificarse por el hecho de su previsión, por razón de la naturaleza temporal de la relación de servicio, en una norma general o abstracta Tras pasar revista a los requisitos previstos en la normativa comunitaria para poder justificarse la existencia de una tal diferencia, el TJUE manifiesta que la administración autonómica se ha limitado en su escrito de alegaciones «a enunciar la existencia de menores requisitos en lo que atañe al nombramiento de los funcionarios interinos y posibles discriminaciones inversas en detrimento de los funcionarios de carrera».

No cuestiona en modo alguno la sentencia el margen de facultad de que disponen los Estados miembros para la aplicación de la Directiva y la posibilidad de establecer requisitos específicos que puedan legalmente diferenciar a colectivos entre los que se citan

requisitos de antigüedad para acceder a determinados puestos, restringir el acceso a la promoción interna a los funcionarios de carrera y exigirles que demuestren tener una 
experiencia profesional correspondiente al grupo inmediatamente inferior al que es objeto del proceso selectivo,

si bien la aceptación de tales criterios de diferenciación procederá siempre y cuando se establezcan de manera transparente y se arbitren los mecanismos de control adecuados para evitar la exclusión de algunos trabajadores por el mero hecho de la duración de su relación laboral.

Por consiguiente, y es importante tenerlo presente en el debate generado sobre cómo transponer adecuadamente la normativa comunitaria y las modificaciones que deberán producirse en la normativa interna, si el trato diferente en relación con un proceso selectivo

resulta de la necesidad de tener en cuenta requisitos objetivos, relativos a la plaza que dicho procedimiento tiene por objeto proveer y que son ajenos a la duración determinada de la relación de servicio que vincula al funcionario interino con su empleador, puede estar válidamente justificado, en el sentido de la cláusula 4, apartados 1 o 4, del Acuerdo marco,

pero en modo alguno lo será un requisito general y abstracto como el de un período de antigüedad, que sí cumple el trabajador interino pero que no les de utilidad jurídica al no ser funcionario de carrera.

Es decir, la mera naturaleza temporal de la relación no puede ser un criterio válido de diferenciación si no va acompañado de un examen detallado las tareas que deben desempeñar los trabajadores, en este caso los docentes, y las características inherentes a las mismas. Repárese además en que todo funcionario de carrera que cumpla el requisito de cinco años de antigüedad podrá acceder a la evaluación docente, mientras que un funcionario interino como el del presente caso, con dieciséis años de antigüedad en la actividad docente, y probablemente con un nivel de experiencia y conocimiento superior al de un buen número de funcionarios de carrera, no podrá presentarse a la evaluación únicamente por el requisito de no ser funcionario de carrera.

Por último, tampoco acepta el TJUE el argumento de la Administración asturiana de que, de validarse la tesis del funcionario interino, se estaría produciendo una situación discriminatoria pero a la inversa, es decir hacia el funcionario de carrera. No niega el TJUE que ello podría ser una razón objetiva de acuerdo a la normativa comunitaria, pero tal objetivo que puede perseguir el legislador nacional no podría justificar

una norma nacional desproporcionada, como la del litigio principal, que excluye por completo y en cualquier circunstancia que se tomen en consideración los períodos de servicio prestados por los empleados públicos en el marco de relaciones de servicio de duración determinada para determinar su antigüedad y, por tanto, su nivel retributivo... 
El Tribunal de Justicia de la Unión Europea y el impacto de Su reciente jurisprudencia en la Regulación DE LA CONTRATACIÓN TEMPORAL EN ESPAÑA Y EL DERECHO A INDEMNIZACIÓN POR EXTINCIÓN DEL CONTRATO

\subsection{Medidas que prevengan el recurso abusivo a contratos de duración determinada. Auto del TJUE de 21 de septiembre de 2016 (asunto C-614/15).}

El auto se dicta con ocasión de una cuestión prejudicial planteada por el tribunal de la localidad rumana de Craiova y que versa sobre la interpretación de la cláusula 5.1 del acuerdo marco. El TJUE dicta auto porque su respuesta se deduce claramente de la jurisprudencia ya existente sobre la materia,

... en particular de las sentencias de 4 de julio de 2006, Adeneler y otros (C 212/04, EU:C:2006:443); de 23 de abril de 2009, Angelidaki y otros (C 378/07 a C 380/07, EU:C:2009:250); de 26 de enero de 2012, Kücük (C 586/10, EU:C:2012:39); de 13 de marzo de 2014, Márquez Samohano (C 190/13, EU:C:2014:146); de 3 de julio de 2014, Fiamingo y otros (C 362/13, C 363/13 y C 407/13, EU:C:2014:2044), y de 26 de noviembre de 2014, Mascolo y otros (C 22/13, C 61/13, C 63/13 y C 418/13, EU:C:2014:2401).

Sólo deseo añadir algunas consideraciones del TJUE que no han merecido mi atención en anteriores comentarios de las tres sentencias y del auto de 14 de septiembre, cuales son que el hecho de que si bien ha de ser el órgano jurisdiccional nacional remitente el que deba comprobar si concurren las causas objetivas para la conformidad a la directiva de un determinado contrato de duración determinada, no es menos cierto que la causa alegada, como necesidad para utilizar la contratación temporal,

... no puede sin embargo deducirse de consideraciones dirigidas a evitar exponer al Estado, como empleador del sector afectado, a cualquier tipo de riesgo financiero... En efecto, aunque las consideraciones de índole presupuestaria puedan ser el motivo de las opciones de política social de un Estado miembro e influir sobre la naturaleza o el alcance de las medidas que éste desea adoptar, no constituyen en sí mismas un objetivo perseguido por esta política y, por lo tanto, no justifican la falta de medidas de prevención de la utilización abusiva de sucesivos contratos de trabajo de duración determinada en el sentido de la cláusula 5, apartado 1, del Acuerdo marco (véanse las sentencias de 24 de octubre de 2013, Thiele Meneses, C 220/12, EU:C:2013:683, apartado 43 y jurisprudencia citada, y de 26 de noviembre de 2014, Mascolo y otros, C 22/13, C 61/13, C 63/13 y C 418/13, EU:C:2014:2401, apartado 110) (apartados 62 y 63).

\subsection{Universidades. Los recortes presupuestarios y el título de doctor} no son causas objetivas para tratar de diferente condición a un profesor funcionario interino que a un profesor funcionario de carrera. Notas al auto del TJUE de 9 de febrero de 2017 (C-443/16), que sigue la saga De Diego Porras

Se trata de una resolución judicial que tiene especial interés para el mundo universitario por versar sobre la diferencia de trato (ya adelanto que no justifi- 
cada según el TJUE) en materia de jornada y salario entre profesorado funcionario interino y profesorado funcionario de carrera. La decisión mediante auto se debe a que en este caso concreto, y siguiendo la consolidada jurisprudencia de la Sala (es particularmente interesante el auto por la amplia relación de sentencias y autos citados que van en la misma línea jurídica), la resolución puede dictarse sin necesidad de acudir a una sentencia ya que la respuesta a las cuestiones prejudiciales "puede deducirse claramente de la jurisprudencia del Tribunal de Justicia», con cita de seis sentencias (entre ellas, ya incluye la dictada en el caso De Diego Porras) y un auto (caso Álvarez Santiso).

Un profesor funcionario interino, desde el muy lejano 7 de noviembre de 1989, que prestaba sus servicios en la Escuela Técnica Superior de Arquitectura, fue el que "encendió la mecha jurídica». En efecto, su jornada y salario fue modificada como consecuencia de la Resolución Rectoral de 10 de octubre de 2012, pasando de prestar servicios a tiempo completo a hacerlo a tiempo parcial, en cuanto que no disponía del título de doctor. No hay mención alguna a un cambio de las funciones desarrolladas por el citado profesor.

Disconforme con la decisión rectoral (la UPM ha sido un buen laboratorio jurídico para que los tribunales dictasen importantes resoluciones, como la sentencia del TS de 24 de junio de 2014 que dictaminó la obligatoriedad de acudir al procedimiento de despido colectivo para extinguir los contratos de un número de interinos que sobrepasaban los umbrales numéricos del art. 51 de la LET), el profesor interpuso recurso contencioso-administrativo, solicitando su anulación. En su escrito, alegaba (vid apartado 16) que la decisión «no respondia a necesidades docentes ni del departamento en el que ejercía funciones docentes, sino únicamente a consideraciones relacionadas con la reducción de los gastos de la Universidad», y que al aplicarse exclusivamente a los funcionarios interinos, la Resolución tenía como efecto "tratarles de manera menos favorable que a los funcionarios de carrera». En la impugnación del recurso, la UPM argumentó (vid apartado 17) que la medida adoptada era "una garantía de calidad que permite medir el rendimiento de las actividades docentes, investigadoras y de gestión del profesorado universitario", y que se había adoptado en el marco de las facultades de autoorganización de que disponen las Administraciones Públicas, constituyendo "una reacción adecuada, habida cuenta del descenso de las matriculas observado en estos últimos años».

En su auto de planteamiento de la cuestión prejudicial, el juzgador español recuerda que el acuerdo marco impide tratar de forma menos favorable a un trabajador por el solo hecho de tener un contrato (en el caso enjuiciado un nombramiento interino) de duración determinada. Subraya igualmente, y me parece importante la referencia, que la Ley Orgánica de Universidades (en redacción de LO 4/2007, de 12 de abril, que modificó la LO 6/2001 de 21 de diciembre) incluyó una disposición adicional (segunda), hoy ya derogada, referida a cómo se 
produciría la integración de los miembros del cuerpo de profesores titulares de Escuelas Universitarias en el de profesores titulares de Universidad, disponiendo su apartado 3 que quienes no accedieran a tal condición, «permanecerán en su situación actual, manteniendo todos sus derechos y conservando su plena capacidad docente y, en su caso, investigadora». Para el juzgador, en realidad esta disposición sólo ha sido aplicada por la Administración Universitaria a los funcionarios de carrera, y no a los interinos, siendo la razón de ser de la diferencia que «los primeros han superado un proceso selectivo que conduce a la creación de un puesto mientras que el nombramiento de los segundos responde sólo a determinados requisitos, vinculados a la necesidad y la urgencia de proveer una plaza vacante».

Va concretando sus dudas el juzgador antes de llegar a concretar la cuestión prejudicial, es decir va dando pistas al TJUE del motivo de su duda-discrepancia con la decisión del Rectorado de la UPM, pistas que sin duda van a tener relevancia en la decisión que adoptará el TJUE, pues si bien este afirma, en el apartado 39, algo que hemos leído en numerosas resoluciones anteriores, esto es que "corresponde, en definitiva, al órgano jurisdiccional remitente» determinar si los dos colectivos, temporales e indefinidos (interinos y funcionarios de carrera en el caso enjuiciado) «se hallan en una situación comparable»..., inmediatamente añade a continuación (y también algo parecido lo encontramos en la sentencia del caso De Diego Porras) que de las indicaciones contenidas en el auto de remisión "se deduce claramente que, en lo que respecta a cada una de estas categorías de profesores, las características de los puestos de trabajo ocupados, la naturaleza del trabajo desarrollado, las tareas confiadas y la formación requerida son idénticas».

¿Y cuáles son esas pistas de la duda-discrepancia del juzgador español? Pues además de lo que reproduce literalmente el apartado 39, que la única razón real de la reducción de jornada (y salario) del personal interino son las restricciones presupuestarias, la necesidad de reducir o limitar los gastos de personal de las Universidades (en este caso concreto de la UPM), aun cuando a efectos académicos «las necesidades docentes del departamento de que se trata permanecen inalteradas, y que, además, las convocatorias recientes demuestran la permanencia de la necesidad de ocupar este puesto a tiempo completo» (apartado 20).

Va concluyendo su argumentación el juzgador nacional, planteándose, antes de formular las cuestiones prejudiciales, si la norma de la UPM, que encuentra su origen en la normativa presupuestaria de la Comunidad de Madrid, que a su vez encuentra su razón de ser en la normativa estatal que estableció restricciones presupuestarias al gasto público a partir de 2012 (y si quieren que sigamos buscando más «orígenes lejanos» nos podemos remontar a la reforma exprés del art. 135 de la CE, consecuencia de decisiones adoptadas por los órganos de gobierno de la Unión Europea) es o no conforme al Acuerdo Marco y en concreto a su cláusula general de no discriminación recogida en el núm.4.1, en cuanto que tiene como consecuencia (más fácil no se lo puede poner, al menos según 
mi parecer, al TJUE) «la reducción a la mitad de la jornada de los profesores funcionarios interinos que no son doctores, mientras que los profesores funcionarios no doctores conservan integramente sus derechos y no sufren ninguna desventaja».

Antes de abordar la resolución del litigio, el TJUE pasa revista a la normativa europea y espańola aplicable. De la primera, la Directiva 1999/70/CE, hay una mención expresa al art. 1 y al párrafo primero del art. 2, mientras que del Acuerdo Marco las menciones expresas son a la cláusula 2 (ámbito de aplicación), 3 (definiciones) y 4.1 (principio de no discriminación). De la segunda, los preceptos más arriba explicados de la Ley Orgánica de Universidades (en su redacción de 2007) y la Ley autonómica madrileña 4/2012 de 4 de julio, también objeto de análisis con anterioridad.

El TJUE se adentra en el examen conjunto de las cuatro cuestiones planteadas, pasando a repasar de forma exhaustiva su jurisprudencia en materia de interpretación y aplicación del Acuerdo Marco, y muy especialmente de lo que afecta al principio general de no discriminación recogido en la cláusula 4, una cláusula de la que el TJUE ha reiterado que es "incondicional y suficientemente precisa para que los particulares puedan invocarla ante un juez nacional».

De las consideraciones generales sobre la consolidada jurisprudencia del TJUE hemos de pasar a su aplicación al caso concreto y en razón de las circunstancias también concretas que concurren en el mismo. Debemos preguntarnos en primer lugar si existe una diferencia de trato entre unos profesores (funcionarios interinos) y otros (funcionarios de carrera), y siendo la respuesta afirmativa, ya que la reducción de jornada y salario sólo se aplica a los primeros, "por la mera razón de que no poseen el título de doctor» (dicho sea incidentalmente, la tesis del TJUE en este caso concreto no debería llevar, ni creo que desde luego sea su intención, a la desvalorización de la importancia, que es mucha, del título de doctor en la vida universitaria).

¿Se da esta diferencia de trato entre trabajadores (funcionarios) que se encuentran, y por ello puede entrar en juego el principio general de no discriminación, «en una situación comparable»? En este punto, la Sala recuerda cuál es el concepto de trabajador con contrato de duración indefinida comparable, y el conjunto de factores que deben tomarse en consideración para efectuar la comparación entre trabajadores (funcionarios) temporales e indefinidos, factores ya referenciados con anterioridad en mi explicación, y que el TJUE ha tomado en consideración en su respuesta dada en el apartado 39, al hilo de las «pistas» dadas por el juez nacional sobre su duda-discrepancia. Pues bien, si la naturaleza de las tareas y actividades del personal académico universitario interino y de carrera son «idénticas», habrá que entrar a examinar y determinar si la naturaleza temporal del vínculo jurídico que une al funcionario interino con su empleador (público), que le diferencia del funcionario de carrera (naturaleza indefinida) 
puede justificar la diferencia de trato entre ambos colectivos, así como también si existe una razón objetiva que la justifique (recuerdo que el apartado 3 de la cláusula 4 dispone que "Las disposiciones para la aplicación de la presente cláusula las definirán los Estados miembros, previa consulta con los interlocutores sociales, y/o los interlocutores sociales, según la legislación comunitaria y de la legislación, los convenios colectivos y las prácticas nacionales»).

Respuesta fácil a la primera cuestión suscitada, esto es la importancia de la naturaleza temporal del vínculo jurídico entre empleador y trabajador, en cuanto que la consolidada jurisprudencia del TJUE ha concluido que no es una razón objetiva el hecho de que la diferencia «esté prevista por una norma nacional y abstracta, como una ley o un convenio colectivo", y por ello la naturaleza temporal, que se da en el caso concreto enjuiciado, de la relación de servicio del personal (profesor funcionario interino) de la Administración Pública (Universidad) «no puede constituir una cláusula objetiva en el sentido de la cláusula 4, apartado 1 del Acuerdo Marco».

Si pasamos a la segunda cuestión, la jurisprudencia del TJUE es muy clara en el sentido de que la diferencia o desigualdad de trato debe estar justificada "por la existencia de elementos precisos y concretos", debe basarse en "criterios objetivos y transparentes», debe responder, al objeto de alcanzar el objetivo perseguido, a «una necesidad auténtica» y resultar "indispensable al efecto», concretando estas pautas generales en la tesis, recogida en numerosas sentencias y autos, de que los elementos de diferenciación "pueden tener su origen, en particular, en la especial naturaleza de las tareas para cuya realización se celebran los contratos de duración determinada y en las características inherentes a las mismas o, eventualmente, en la persecución de un objetivo legitimo de politica social por parte de un Estado miembro».

¿Cuáles son las razones aducidas por la UPM para justificar la diferencia de trato? Básicamente, razones económicas de restricciones presupuestarias y caída en el número de estudiantes matriculados (o más exactamente a mi parecer del número de créditos matriculados por cada estudiante, una tendencia observable en la mayor parte de las Universidades públicas desde el inicio de la crisis económica y social en 2008 y su exacerbación a partir de 2011), que llevan a su equipo de gobierno a la adopción de medidas que considera más adecuadas para revertir la situación, siempre dentro del marco de su potestad de autoorganización.

¿Puede adoptar medidas las Administraciones Públicas, en el marco autoorganizativo, que establezcan regulaciones que no vulneren la Directiva de 1999 y el acuerdo marco? La respuesta es afirmativa, y el auto recuerda que el TJUE las ha aceptado en casos tales como el establecimiento de "requisitos de antigüedad para acceder a determinados puestos, restringir el acceso a la promoción interna a los funcionarios de carrera y exigirles que demuestren tener una experiencia profe- 
sional correspondiente al grupo inmediatamente inferior al que es objeto del proceso selectivo». Ahora bien, una vez afirmada la posibilidad de que disponen las Administraciones Públicas, se recuerda que la potestad de autoorganización no está exenta de controles, al objeto de que los criterios utilizados que conllevan una diferencia de trato impliquen una diferencia injustificada, es decir una discriminación, hacia los trabajadores (funcionarios) con contratos (nombramientos) de duración determinada.

Más finezza jurídica en la argumentación del TJUE y que conviene ahora recordar: cuando el trato diferente guarda relación con un proceso selectivo puede estar justificada la diferencia de trato, puede ser una razón objetiva prevista en el apartado 4.1 del Acuerdo Marco, si resulta «de la necesidad de tener en cuenta requisitos objetivos, relativos a la plaza que dicho procedimiento tiene por objeto proveer y que son ajenos a la duración determinada de la relación de servicio que vincula al funcionario interino con su empleadon;; pero, no será en modo alguno conforme a la normativa comunitaria una diferencia, que ha implicado reducción de tiempo de trabajo y de salario, como la que es objeto de enjuiciamiento, y que se basa en la diferencia de disposición de un título académico, el de doctor, y que no toma en consideración "otros criterios objetivos y transparentes vinculados más concretamente a la naturaleza o al objeto del puesto de trabajo de que se trata». Estamos en presencia de dos colectivos (funcionarios interinos y funcionarios de carrera) que desempeñan «funciones similares» (obsérvese que en alguna ocasión el TJUE se refiere a funciones «idénticas» y en este caso efectúa una manifestación light al referirse a las mismas), cuya duración del vínculo jurídico y la disposición de un determinado título académico no deben afectar a la aplicación de principio de igualdad de trato y no discriminación en las condiciones de trabajo.

¿Y qué decir de las restricciones presupuestarias? ¿Son o pueden ser una causa objetiva que justifique la diferencia de trato? Es consolidada la jurisprudencia del TJUE que da una respuesta negativa a dicha pregunta, por considerar que ello implicaría una discriminación hacia el colectivo de trabajadores (funcionarios) temporales. Así nos lo recuerda en el apartado 53:

aunque las consideraciones de índole presupuestaria puedan ser el motivo de las opciones de política social de un Estado miembro e influir sobre la naturaleza o el alcance de las medidas que éste desea adoptar, no constituyen en sí mismas un objetivo perseguido por esta política y, por lo tanto, no justifican la aplicación de una normativa nacional que conduce a una diferencia de trato en detrimento de los trabajadores con contrato de duración determinada.

Pero además, y siempre de acuerdo con las «pistas» facilitadas por el juzgador nacional, el TJUE llega a la conclusión de que las alegaciones de la UPM tampoco se basan en criterios objetivos y transparentes, ya que «los hechos contradicen estas alegaciones, como ha señalado el propio juzgado remitente, ya que las necesidades de los servicios de que se trata han permanecido inalteradas y las recien- 
El Tribunal de Justicia de la Unión Europea y el impacto de Su reciente jurisprudencia en la Regulación DE LA CONTRATACIÓN TEMPORAL EN ESPAÑA Y EL DERECHO A INDEMNIZACIÓN POR EXTINCIÓN DEL CONTRATO

tes convocatorias para proveer puestos a tiempo completo demuestran lo contrario de lo que se alega».

Colofón de todo lo anteriormente expuesto es el fallo del auto: la cláusula 4.1 debe interpretarse

en el sentido de que se opone a una norma nacional, como la controvertida en el litigio principal, que autoriza, en el marco de medidas de reestructuración de la organización universitaria, a las administraciones competentes del Estado miembro de que se trata a reducir a la mitad la jornada laboral de los Profesores Titulares de Escuela Universitaria que sean funcionarios interinos, debido a que no poseen el título de doctor, mientras que los Profesores Titulares de Escuela Universitaria funcionarios de carrera que tampoco poseen el título de doctor no son objeto de la misma medida.

\section{Sigue la saga De Diego Porras..., aunque sea por omisión o silencio. Sentencia del TS de 28 de marzo de 2017. Indemnización de 20 días/año para personal indefinido no fijo en caso de cobertura de la plaza y subsiguiente extinción contractual}

La sentencia, dictada en Pleno y que obtuvo la unanimidad de sus miembros, desestima los dos recursos de casación para la unificación de doctrina interpuestos por las partes empresarial y trabajadora, y confirma la sentencia dictada por la Sala de lo Social del Tribunal Superior de Justicia de Madrid el 11 de febrero de 2015, de la que fue ponente el magistrado José Ramón Fernández, que había estimado el recurso de suplicación interpuesto por la parte trabajadora contra la sentencia dictada por el Juzgado de lo Social núm. 20 de Madrid el 16 de abril de 2014.

En apretada síntesis, y por lo que respecta ahora al objeto de mi exposición, el JS desestimó la demanda interpuesta por despido improcedente de una trabajadora del Consejo Superior de Investigaciones Científicas (CSIC), mientras que el TSJ madrileño estimó parcialmente el recurso y reconoció el derecho de la recurrente a percibir una indemnización de 20 días de salarios/año por la extinción de su contrato como consecuencia de la cobertura de la plaza que ocupaba, con contrato indefinido no fijo, por haber salido a concurso en régimen funcionarial.

Cabe destacar que el litigio encuentra su origen en la demanda interpuesta por una trabajadora del CSIC, tras la comunicación de la extinción de su contrato de trabajo. Según los hechos probados de la sentencia de instancia, recogidos en el antecedente de hecho primero de la resolución del TS, dicha trabajadora tenía la categoría profesional de titulada superior de investigación y laboratorio, habiendo iniciado la prestación de sus servicios el 1 de abril de 
2003, y tras demanda interpuesta en sede judicial obtuvo la condición de trabajadora indefinida no fija, por sentencia del Juzgado de lo Social núm. 9 de Madrid dictada el 16 de marzo de 2009.

El interés del litigio se centra en cómo abordará el Pleno de la Sala Social la argumentación de la abogacía del Estado sobre la cuantía de la indemnización a percibir por la persona trabajadora que ve extinguido su contrato por la cobertura de la plaza que ocupaba.

La sentencia de contraste, que aplicó la indemnización de 8 días de salario/año (art. 49.1 b LET, en la redacción aplicable al momento de producirse el conflicto) fue la dictada por el TSJ madrileńo el 26 de mayo de 2014, en un conflicto que afectó a un trabajador de la misma empresa ahora demandada, por lo que la contradicción es clara y evidente (indemnización de 8 o 20 días de salario/año), afirmando con acierto la Sala que

la contradicción exigida por el art. 219.1 LRJS no puede ser aquí más evidente, pues no sólo estamos ante debates análogos, sino que se produce en relación a situaciones fácticas idénticas y, no obstante, las sentencias comparadas llegan a soluciones diametralmente opuestas.

¿Cuál es la fundamentación jurídica de la tesis defendida por la que fuera parte demandada y después recurrente? La vulneración del art. 49.1.b) LET en relación con el apartado c) del mismo precepto y con la disposición transitoria $13 .{ }^{\text {a }}$ (que pasa a ser octava en el texto refundido aprobado por RDLeg. 2/2015, de 23 de octubre). No obstante, parece advertirse una cierta contradicción en la tesis argumental, y así también lo pone de manifiesto la Sala, ya que en primer término cuestiona que la indemnización regulada en el art. 49.1.c) LET sea aplicable a otros supuestos de extinción contractual (por lo que la tesis a defender sería la validez de la decisión del juzgador de instancia de extinguir el contrato sin indemnización alguna), pero inmediatamente cuestiona que la tesis del TSJ madrileño, la fijación de una indemnización de 20 días de salario/ańo, sea conforme a derecho, por deber serlo la de ocho días prevista en el citado precepto de la LET.

Es partir de aquí cuando la Sala va a proceder a la resolución del caso, y si debiéramos hacer caso a la manifestación contenida en el apartado 3, tercer párrafo, del fundamento de derecho tercero, la respuesta parece que sería la misma que la plasmada en una abundante jurisprudencia consolidada desde hace ya dos años, con un elenco de sentencias que se listan y cuya doctrina se resume en la más reciente de 7 de noviembre de 2016 y que es ampliamente transcrita, en cuanto que la sentencia afirma que la cuestión planteada

viene siendo objeto de múltiples controversias, la mayoría de ellas ya abordadas por esta Sala IV del Tribunal Supremo que ya ha sentado doctrina y establecido criterios 
a los que se debe estar con relación con las consecuencias del cese de los trabajadores indefinidos no fijos del sector público, habiéndose resuelto que corresponde el abono de la indemnización al art. 49.1.c) del ET.

Pero, inmediatamente a continuación, la Sala expone que «un examen más profundo de la cuestión» (no se conocen más detalles de dicho examen, que ciertamente sería bueno conocer para analizar con conocimiento de causa el cambio de criterio del TS) le ha llevado a la aplicación de un criterio diferente sobre la cuantía de la indemnización, que va a traducirse en un «nuevo criterio cuantitativo», que será el del acogimiento de los 20 días de salario año (y no los 8 o más, hasta 12, anteriores en aplicación del art. 49.1.c) LET). Nuevo criterio que se construye a partir de la argumentación que se expone y analiza a continuación:

a) En primer lugar, la Sala arguye que si bien la figura del trabajador con contrato indefinido no fijo es de construcción jurisprudencial, ya se encuentra recogida en la normativa aplicable al empleado público, actualmente el RDL 5/2015 de 30de octubre, por el que se aprueba el texto refundido de la Ley del Estatuto Básico del Empleado Público. Al referirse a esta norma, y en concreto a los arts. 8.1 y 11.1, explica que los mismos

... nos muestran que la norma diferencia al personal laboral en función de la duración de su contrato en fijo, por tiempo indefinido o temporal, pues en otro caso no habría empleado el vocablo indefinido y sólo habría distinguido entre fijos y temporales, lo que conlleva que el personal indefinido no sea equiparable al temporal.

$\mathrm{Al}$ respecto, sorprende que esta argumentación se realice en esta ocasión y no se haya hecho con anterioridad, ya que los citados preceptos del EBEP datan de su originaria redacción de la Ley 7/2007 de 12 de abril. Por otra parte, esta construcción demuestra la dificultad jurídica de diferenciar entre trabajadores indefinidos no fijos y temporales en caso como el ahora enjuiciado, ya que el hecho de convocarse una plaza y poder significar la extinción del contrato del trabajador indefinido no fijo demuestra que su acercamiento al trabajador temporal es algo más que una mera hipótesis de trabajo, aunque se trate de una temporalidad que puede alargarse en el tiempo en razón de las circunstancias que posibiliten, o no, que la plaza "provisionalmente ocupada» salga a concurso para su acceso en régimen funcionarial.

b) En segundo lugar, la Sala residencia el origen de esta modalidad contractual, y no le falta razón, «en un uso abusivo de la contratación temporal por parte de algún órgano administrativo», y destaca las diferencias entre la regulación fraudulenta de un contrato temporal en el sector privado y en el sector público (volvemos a la cuestión anterior de la di- 
ficultad de diferenciar entre el trabajador «indefinido no fijo» y el «temporal»), ya que en el primero la normativa vigente dispone su conversión en contrato fijo ex art 15.3 y 5 de la LET (si bien el término «fijo» sólo se utiliza en el segundo apartado citado, no es menos cierto, o al menos así lo creo, que el término «indefinido» utilizado en el apartado 3 tiene una connotación equivalente), en el segundo no es posible que ello se produzca ya que el acceso a tal condición de fijeza requiere el acceso con cumplimiento y respeto de los principios constitucionales recogidos en el art. 103.3 de la CE y que lo han sido después en varios preceptos del EBEP, cuales son los de igualdad, mérito y capacidad.

En suma, la diferencia radicaría en que en caso de una contratación fraudulenta (me pregunto si sólo en origen o convertida en irregular por el paso del tiempo y el incumplimiento de los requisitos requeridos para proceder a la extinción de un contrato temporal)

no puede imponerse esa novación sancionadora de la relación jurídica, por cuanto se facilitaría, igualmente, un acceso fraudulento a un empleo público, al eludirse la aplicación de las normas que velan por el acceso a esos puestos funcionariales y laborales, mediante concursos públicos en los que se respeten los principios de igualdad, mérito y capacidad.

Una tesis cierta, pero incompleta a mi parecer ${ }^{4}$.

c) Vayamos al tercer argumento, que es consecuencia de los dos anteriores, y que por consiguiente no se formularía si no se hubieran expuesto, argumentado y resuelto en los términos que lo han sido. Si estamos en presencia de una modalidad contractual diferente por una parte de la del contrato temporal, y por otra de la del trabajador fijo, podemos preguntarnos, y así lo hace la Sala, cuál puede ser la indemnización a percibir por un trabajador que ve extinguida la relación laboral por cobertura reglamentaria de la plaza que ocupaba, y en este punto la Sala formula una tesis con la que sin duda se puede estar de acuerdo, y así es por mi parte, pero que nuevamente requeriría de una mayor argumentación jurídica. El hecho de que la extinción se produzca cuando estamos en presencia de un contrato no temporal, que tiene una indemnización actualmente fijada de 12 días de salario/año cuando se trata de un contrato

\footnotetext{
${ }^{4}$ Es acertado el planteamiento del profesor Beltrán de Heredia al afirmar que la tesis es sólo parcialmente cierta "porque una relación indefinida no fija también puede producirse en casos de contratación temporal lícita si se supera un determinado plazo de tiempo", tal como he apuntado con anterioridad, "y también en casos de subrogación de empresa (reversión de servicios públicos)", un supuesto por cierto que cada vez más se está planteando por ayuntamientos surgidos de las elecciones municipales de mayo de 2015 que están gobernados por fuerzas políticas de izquierdas. http://ignasibeltran. com/2017/04/10/que-es-un-indefinido-no-fijo-a-proposito-de-la-sts-28317/ (documento consultado el 22 de abril de 2017).
} 
El Tribunal de Justicia de la Unión Europea y el impacto de Su reciente jurisprudencia en la Regulación DE LA CONTRATACIÓN TEMPORAL EN ESPAÑA Y EL DERECHO A INDEMNIZACIÓN POR EXTINCIÓN DEL CONTRATO

para obra o servicio o por necesidades de la producción, lleva a la Sala a pensar que tal cuantía "parece insuficiente» porque

... dadas las causas que han motivado la creación de esta institución, parece necesario reforzar la cuantía de la indemnización y reconocer una superior a la establecida para la terminación de los contratos temporales, pues el vacío normativo al respecto no justifica, sin más, la equiparación del trabajador indefinido-no fijo a temporal como hemos venido haciendo.

Es decir, por una parte el TS entona un «mea culpa» por no haber actuado de esta forma en casos anteriores (me pregunto si las sentencias del TJUE de 14 de septiembre de 2016, especialmente la del caso De Diego Porras, y los debates académicos, judiciales y mediáticos que han generado, no habrán tenido algo que ver, o mucho, con este cambio, aunque parece que esté casi prohibido citar al TJUE, a la espera, quizás, de nuevas sentencias que clarifiquen las dudas existentes), y por otra no tiene miedo alguno a convertirse en legislador, aunque sea bajo el argumento de que la normativa vigente debe llevar a diferenciar las indemnizaciones a percibir según que la extinción sea de un contrato indefinido no fijo o un contrato temporal.

d) Por último, la Sala, tras recordar que el EBEP ha incorporado al marco normativo vigente la figura contractual del indefinido no fijo pero sin concretar elementos propios de su regulación, como podría ser, por lo que nos interesa en este caso concreto, el régimen extintivo, es del parecer que debe ser ella la que lo fije (es decir, ejerciendo tareas de legislador), y cree que estamos en presencia de un supuesto que puede encontrar puntos de comparación con otros regulados en la LET, cuales son las extinciones contractuales por causas objetivas, recogidas en el art. 52 de la LET y a las que la propia norma, en su art. 53.1, reconoce el derecho de quien vea extinguido su contrato a percibir una indemnización de 20 días de salario por año de servicio y un máximo de 12 mensualidades.

Pero..., el TS hila muy fino para llegar a la conclusión relativa a la fijación de la cuantía de 20 días, ya que no considera exactamente "encajable» esta extinción en algunas de las reguladas en el art. 52 LET, añadiendo que ese posible encaje "sería complejo», sino "asimilable» a las mismas, es decir "a las que el legislador considera como circunstancias objetivas que permiten la extinción indemnizada del contrato». Nuevamente nos quedamos con una tesis que altera las reglas del juego jurisprudenciales anteriores, y que, al margen del reconocimiento de su ajuste al marco normativo vigente, estatal y europeo (aunque reitero que parece que la Sala se haya impuesto la «autoobligación» de no citar la sentencia De Diego Porras), hubiera debido merecer una mayor explicación. 